\title{
Mitral insufficiency with a double-orifice mitral valve in an adult patient
}

\author{
Stefano Congiu, MD, Miguel Josa, MD, Xavier Freixa, MD, Manuel Azqueta, MD, Carlos Mestres, MD, PhD,
} and Jaime Mulet, MD, PhD, Barcelona, Spain

Supplemental material is available online.

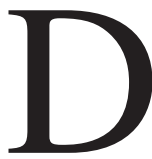

ouble-orifice mitral valve (DOMV) is a rare congenital abnormality. Isolated occurrences of this defect are uncommon, and they are usually associated with other congenital heart defects.

\section{Clinical Summary}

A 64-year-old woman was found to have a heart murmur suggestive of mitral regurgitation during a routine clinical examination. The patient had a past history of arterial hypertension. She complained of gradually progressive dyspnea for 6 months before admission.

Transesophageal echocardiography showed dilatation of the left and right atria and ventricles, severe mitral regurgitation, moderate tricuspid regurgitation, a large aneurysm of the interatrial septum, and severe pulmonary hypertension. The mitral valve was divided in two by the presence of a middle structure, which created a functional double-orifice valve (Figure 1).

This middle structure was thickened and prolapsed markedly into the atrium during systole, leading to severe mitral regurgitation. Mitral valve chordae tendinae were attached to an anterior papillary muscle and to several muscular outpouchings of the posterior wall, but a posterior papillary muscle could not be demonstrated. The tricuspid valve was incompetent.

Cardiopulmonary bypass was instituted through a standard median sternotomy and arterial and bicaval cannulation. The left atrial cavity was approached through the right atriotomy and septal defect. A large septal aneurysm in the area of the fossa ovalis was found and resected. The anterior and posterior mitral leaflets were thickened. From the operator's viewpoint, the larger orifice was right, and the smaller was left. They were separated by a tissue bridge connecting the A2 and P2 segments of the valve, which created a double-orifice valve with an anterior and a posterior

\footnotetext{
From the Department of Cardiovascular Surgery, Hospital Clinic Barcelona, University of Barcelona, Barcelona, Spain.

Received for publication Nov 3, 2006; accepted for publication Nov 16, 2006.

Address for reprints: Stefano Congiu, MD, Universite degli studi di Parma, Department of Cardiac Surgery, Via Gramsci 14, Parma 43100, Italy (E-mail: scongiu@tiscali.it).

J Thorac Cardiovasc Surg 2007;134:250-1

$0022-5223 / \$ 32.00$

Copyright @ 2007 by The American Association for Thoracic Surgery

doi:10.1016/j.jtcvs.2006.11.074
}

opening. It was noted that the connecting tissue bridge was also supported by its own chordae tendineae, as if the valve actually had a trileaflet structure (Figure 2). The middle bridge was thickened, and it prolapsed severely into the left ventricle. The anterior leaflet chordae and the most lateral chordae of the posterior leaflets attached to a normally appearing anterior papillary muscle. The chordae of the tissue bridge and some of the posterior leaflet attached to several small muscular outpouchings of the posterior wall of the left ventricle.

The valve was not considered suitable for repair and was therefore replaced with a mechanical bileaflet Sorin Bicarbon prosthesis (Sorin Bomedica, Saluggia, Italy). A tricuspid annuloplasty was performed. However, a persistent atrioventricular block was documented postoperatively, which required insertion of a permanent pacemaker. She was discharged from the hospital on the 13th postoperative day. She is leading an active normal life.

\section{Discussion}

DOMV is a rare abnormality, with the first case described in a postmortem study in $1876 .{ }^{1}$ DOMV is a consequence of an abnormal development of the endocardial cushions. A morphogenetic mechanism of this type of DOMV is explained by an abnormal union into a single structure between the dorsal endocardial and the left lateral endocardial cushions during an early developmental stage. ${ }^{2}$ The most accepted classification was described by Trowitzsch and colleagues in $1985,{ }^{3}$ which defines 3 different types: the hole type ( 2 structured orifices with their own subvalvular apparatus [SA]), complete bridging (1 orifice divided by a complete bridge with a shared SA, the most common), and incomplete bridging (1 orifice divided by an incomplete bridge with shared SA).

DOMV is usually detected at an early age because it is associated with other cardiac abnormalities. The most frequent is atrioventricular canal, which is very common in the case of posteromedial accessory orifice.

At the time of diagnosis, functional valve dysfunction is commonly absent, and most of the patients are asymptomatic.

DOMV is frequently associated with abnormalities of the SA. These malformations might involve the chordae tendineae (redundant, abnormal attachment, chordal ring, and parachute type) and the papillary muscles (supranumerary, fused and abnormal attachment).

Transesophageal echocardiography is the key diagnostic tool providing the most detailed information about cardiac anatomy, the best view of the structure, and valve anatomy.

Three strategies have been described in the correction of DOMV: major valve repair, cleft suture, and valve replacement. ${ }^{4}$ The tissue bridge is responsible for keeping the valve competent, and therefore in case of valve repair, the bridging leaflet should not 


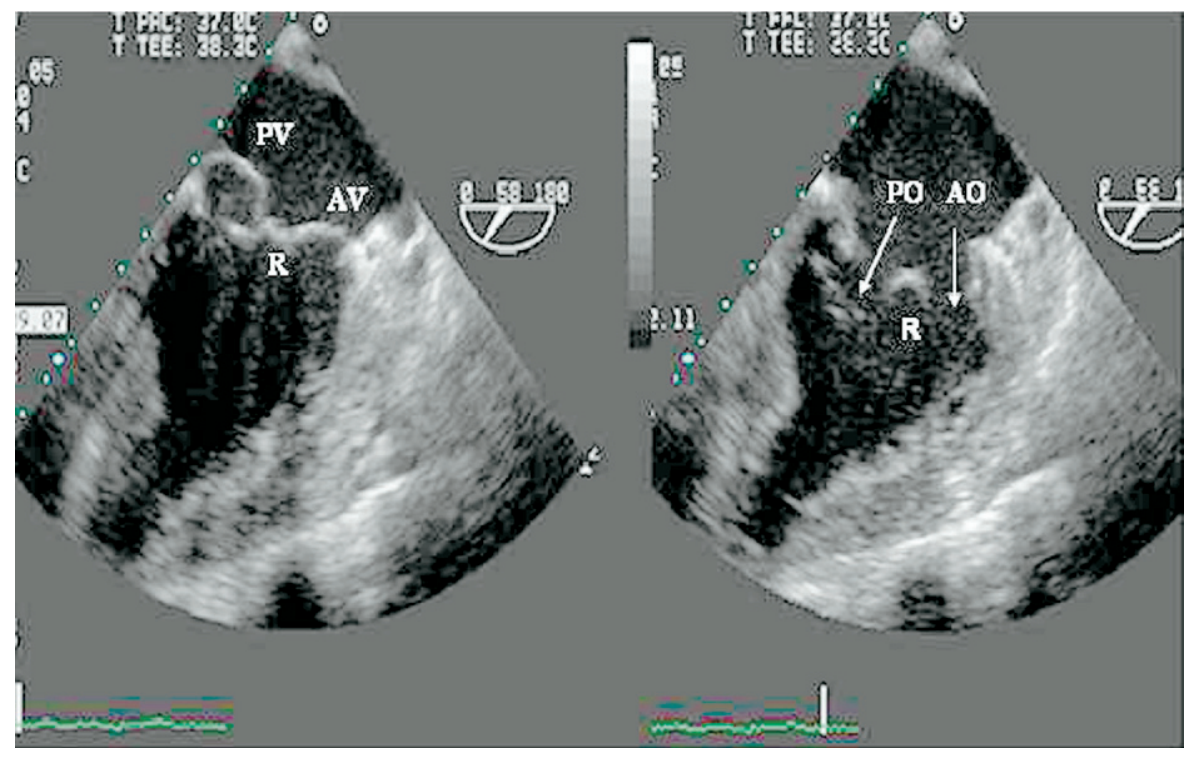

Figure 1. Transesophageal echocardiography showed a severe prolapse of the posterior leaflet of the posteromedial orfice and a well-defined bridge with its own subvalvular apparatus that divided the mitral valve into a double-orifice structure. $P V$, posterior valve; $A V$, anterior valve; $R$, rafe (bridge); $P O$, posterior orifice; $A O$, anterior orifice.

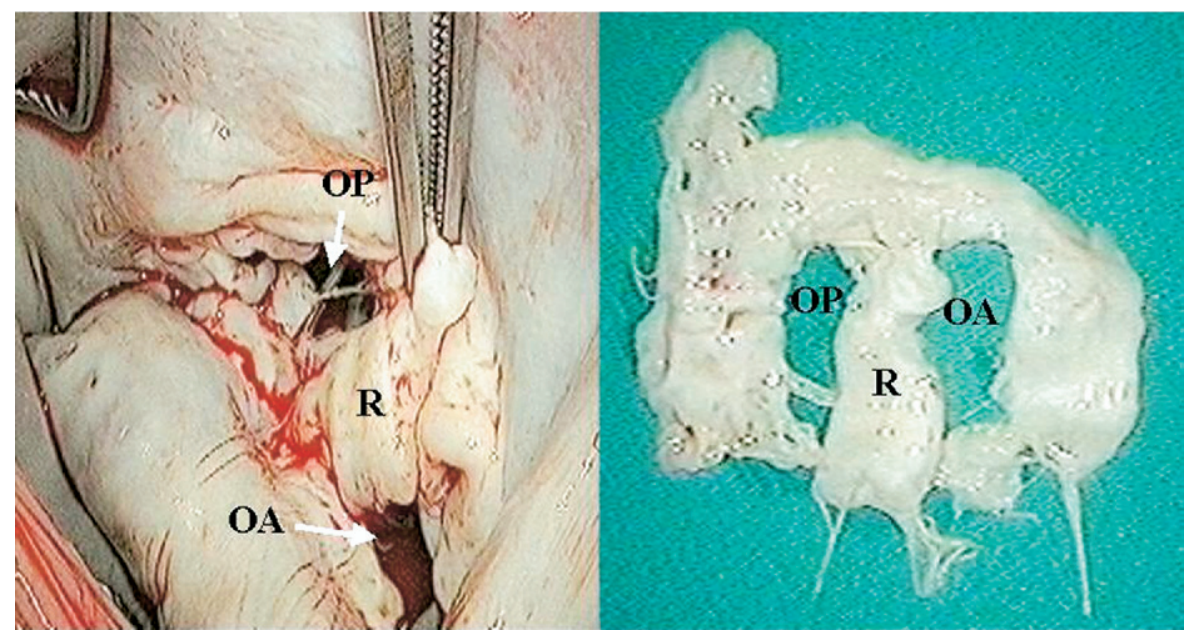

Figure 2. Intraoperative view of the mitral valve showing two different mitral orifices separated by a tissue bridge. The larger orifice (right) was posteromedial and the smaller (left) was anterolateral. After valve resection, we could see a reconstruction of the two mitral orifices with a big tissue bridge supported and attached by its own chordae tendineae. $O P$, posterior orifice; $R$, rafe (bridge); $O A$, anterior orifice.

be divided. ${ }^{4}$ However, in the case of extensive or complicated mitral defects, valve replacement is the preferred technique.

The development of postoperative heart block in this patient was unexpected, because the abundant native valve annular tissue helped in placing the sutures far from the predicted location of the conduction tissue. As has been discussed previously, DOMV is a consequence of an abnormal development of the endocardial cushions, and abnormal conduction abnormalities have been well described in several congenital endocardial cushion defect diseases. ${ }^{5}$ This case suggests that some patients with DOMV might have an abnormal location of the conduction bundles, which could lead to perioperative conduction complications.

\section{References}

1. Greenfield WS. Double mitral valve. Trans Path Soc London. 1876;27: $128-9$.
2. Elfenbein B, Palplanus SH. Duplication of the mitral and tricuspid valves. Arch Pathol. 1968;85:675-80.

3. Trowitzsch E, Bano-Rodrigo A, Burger BM, Colan SD, Sanders SP. Two-dimensional echocardiographic findings in double orifice mitral valve. J Am Coll Cardiol. 1985;6:383-7.

4. Baño-Rodrigo A, Van Praagh S, Trowitzsch E, Van Praagh R. Doubleorifice mitral valve: a study of 27 postmortem cases with developmental, diagnostic and surgical considerations. Am J Cardiol. 1988;61: $152-60$.

5. Thiene G, Wenink ACG, Frescura C, Wilkinson JL, Gallucci V, Ho SY, et al. Surgical anatomy and pathology of the conduction tissues in atrioventricular defects. J Thorac Cardiovasc Surg. 1981;82:928-37.

\section{Appendix Supplementary data}

Supplementary data associated with this article can be found, in the online version, at doi: 10.1016/j.jtcvs.2006.11.074. 